\title{
Nutrient intakes and bone mineral density of post-menopausal women residing in Northern Ireland
}

\author{
M. M. Slevin ${ }^{1}$, P. Allsopp ${ }^{1}$, M. P. Bonham ${ }^{2}$, P. J. Magee ${ }^{1}$, J. M. W. Wallace ${ }^{1}$, J. J. Strain ${ }^{1}$ \\ and E. M. McSorley ${ }^{1}$ \\ ${ }^{1}$ Northern Ireland Centre for Food and Health, University of Ulster, Coleraine BT52 1SA and ${ }^{2}$ Department of Nutrition and \\ Dietetics, Faculty of Medicine, Nursing and Health Sciences, Monash University, 246 Clayton Road, Clayton VIC 3168, \\ Australia
}

Genetic factors explain about $80 \%$ of bone strength ${ }^{(1)}$, however, bone mineral density (BMD) and bone metabolism are also affected by a number of environmental, hormonal and modifiable lifestyle factors, of which diet has been shown to play a prominent role ${ }^{(2)}$. Oestrogen depletion that occurs during the menopause has a negative effect on BMD, putting post-menopausal women at a greater risk of low BMD or osteoporosis $^{(3)}$. The aim of this study was to compare intakes of macro- and micronutrients associated with bone health, between women with osteopenia and those with a normal BMD.

Post-menopausal women ( $n$ 300) (45-75 years) were recruited between October 2008 and June 2009. Nutrient intakes were estimated for 291 women from 4-d food diaries. BMD was measured in the first to fourth lumbar vertebrae (L1-L4) and left proximal femur by dual-energy X-ray absorptiometry.

Osteopenic women had significantly lower estimated dietary intakes of $\mathrm{Ca}$, $\mathrm{P}$ and protein than those with normal BMD, with intakes of Ca below the UK reference nutrient intakes $(\mathrm{RNI})^{(4)}$ (Table 1). Spearman's rank analysis revealed a positive correlation between protein intake $(\mathrm{g} / \mathrm{d})$ and femoral BMD $(r=0.02, P=0.041)$, albeit no relationship between dietary Ca or P and BMD was found. Both groups had median intakes of $\mathrm{Mg}$ and vitamin D below the RNI.

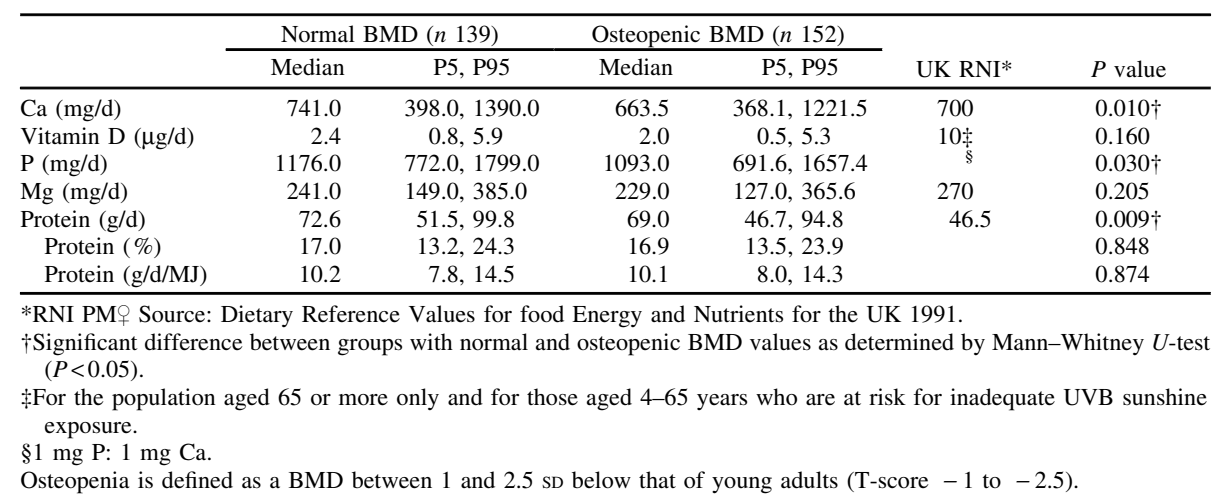

Osteopenia was associated with lower intakes of bone related nutrients among post-menopausal women in Northern Ireland. Vitamin D intake was low in both groups; suboptimal vitamin D intakes have been reported before in post-menopausal women in Ireland ${ }^{(5)}$ and is an area for concern. Dietary advice to older women to optimise intakes of Ca, vitamin D and trace elements may have a beneficial effect on bone health.

1. Pocock NA, Eisman JA, Hopper JL et al. (1987) J Clin Invest 80, 706-710.

2. Salminen H, Sääf M, Johansson SE et al. (2006) Eur J Clin Nutr 60, 486-493.

3. Massé PG, Dosy J, Tranchant CC et al. (2004) J Hum Nutr Dietet 17, 121-132.

4. Department of Health (1991) Dietary Reference Values for Food Energy and Nutrients for the UK, Report of the Panel on Dietary Reference Values of the Committee on Medical Aspects of Food Policy. London: TSO.

5. Hill TR, O’Brien MM, Lamberg-Allardt C et al. (2006) Am J Clin Nutr 88, 1535-1542. 